\title{
Synaptic Reorganization in the Substantia Gelatinosa After Peripheral Nerve Neuroma Formation: Aberrant Innervation of Lamina II Neurons by A $\beta$ Afferents
}

\author{
Ikuhide Kohama, Kuniko Ishikawa, and Jeffery D. Kocsis \\ Department of Neurology and PVAVEPVA Neuroscience Research Center, Yale University School of Medicine, New \\ Haven, Connecticut 06510, and Rehabilitation Research Center, Veterans Affairs Medical Center, West Haven, \\ Connecticut 06516
}

Intracellular recording and extracellular field potential (FP) recordings were obtained from spinal cord dorsal horn neurons (laminae I-IV) in a rat transverse slice preparation with attached dorsal roots. To study changes in synaptic inputs after neuroma formation, the sciatic nerve was sectioned and ligated 3 weeks before in vitro electrophysiological analysis. Horseradish peroxidase labeling of dorsal root axons indicated that $A \beta$ fibers sprouted into laminae I-II from deeper laminae after sciatic nerve section. FP recordings from dorsal horns of normal spinal cord slices revealed long-latency synaptic responses in lamina II and short-latency responses in lamina III. The latencies of synaptic FPs recorded in lamina II of the dorsal horn after sciatic nerve section were reduced. The majority of monosynaptic EPSPs recorded with intracellular microelectrodes from lamina II neurons in control slices were elicited by high- threshold nerve stimulation, whereas the majority of monosynaptic EPSPs recorded in lamina III were elicited by lowthreshold nerve stimulation. After sciatic nerve section, 31 of 57 (54\%) EPSPs recorded in lamina II were elicited by lowthreshold stimulation. The majority of low-threshold EPSPs in lamina II neurons after axotomy displayed properties similar to low-threshold EPSPs in lamina III of control slices. These results indicate that reoccupation of lamina II synapses by sprouting $A \beta$ fibers normally terminating in lamina III occurs after sciatic nerve neuroma formation. Furthermore, these observations indicate that the lamina II neurons receive inappropriate sensory information from low-threshold mechanoreceptor after sciatic nerve neuroma formation.

Key words: axotomy; neuroma; synaptic reorganization; dorsal horn; substantia gelatinosa; $A \beta$ afferents; pain
Peripheral nerve injury results in the vacation of synaptic sites within the substantia gelatinosa of superficial dorsal horn of the spinal cord as a consequence of transganglionic degeneration (Arvidsson et al., 1986; Kapadia and LaMotte, 1987; Himes and Tessler, 1989). Atrophy of nonmyelinated C fibers has been implicated in this synaptic loss (Knyihar-Csillik et al., 1987; CastroLopes et al., 1990; Coggeshall et al., 1997). Moreover, axotomy elicits long-lasting sprouting of A fibers into lamina II, an area in which they do not normally terminate, and inappropriate synaptic formation by the sprouting A fibers (Woolf et al., 1992, 1995; Shortland and Woolf, 1993; Koerber et al., 1994). These degenerative and regenerative changes result in a structural reorganization of highly ordered laminar synaptic termination fields in the dorsal horn of the spinal cord, which may modify sensory input to the CNS (Woolf et al., 1992). It has been suggested from these anatomical observations that central synaptic reorganization after nerve injury may contribute to tactile allodynia, a phenomenon whereby normally non-noxious cutaneous stimuli induce noxious sensation (Woolf et al., 1992; Shortland and Woolf, 1993).

We investigated changes in synaptic transmission between

\footnotetext{
Received Sept. 21, 1999; revised Dec. 7, 1999; accepted Dec. 8, 1999.

This work was supported in part by the Medical Research Service of Department of Veterans Affairs and National Institutes of Health Grant NS10174.

Correspondence should be addressed to Dr. Jeffery D. Kocsis, Department of Neurology, Yale University School of Medicine, Neuroscience Research Center, (127A), Veterans Affairs Medical Center, West Haven, CT 06516. E-mail: jeffery.kocsis@yale.edu.

Copyright (C) 2000 Society for Neuroscience $\quad 0270-6474 / 00 / 201538-12 \$ 15.00 / 0$
}

sprouting terminals of afferent fibers and dorsal horn neurons in an in vitro spinal cord slice preparation of the adult rat 3 weeks after in vivo peripheral nerve section and ligation where a neuroma was found. In spinal cord slice preparations from immature (Urban and Randic, 1984; Gerber and Randic, 1989; Gerber et al., 1991; Randic et al., 1993) and more mature (Yoshimura and Jessell, 1989, 1990; Baba et al., 1999) rats, dorsal root stimulation has been shown to evoke fast and slow EPSPs in dorsal horn neurons. Superficial dorsal horn neurons (laminae I-II) receive primarily monosynaptic inputs from $\mathrm{A} \delta$ fibers and $\mathrm{C}$ fibers, whereas, deep dorsal horn neurons (laminae III-V) receive monosynaptic and polysynaptic inputs from $\mathrm{A} \beta$ fibers, resulting in a complex response to supramaximal primary afferent stimulation (King et al., 1988; Todd, 1989; Miller and Woolf, 1996). A recent electrophysiological study using an in vitro spinal cord slice preparation has demonstrated that peripheral inflammation can facilitate $\mathrm{A} \beta$ fiber-mediated synaptic inputs to the substantia gelatinosa (Baba et al., 1999). We studied field potentials (FPs) and EPSPs in dorsal horn in a spinal cord slice preparation with attached dorsal roots from adult rats (L4-L5) using extracellular and intracellular recording techniques with or without previous sciatic nerve section and ligation. Our results indicate changes in EPSP timing, threshold, and composition that are commensurate with the establishment of inappropriate new synapses in lamina II of dorsal horn after nerve injury, but no change was observed in lamina III.

A preliminary report of this work has been published in abstract form (Kohama et al., 1998). 

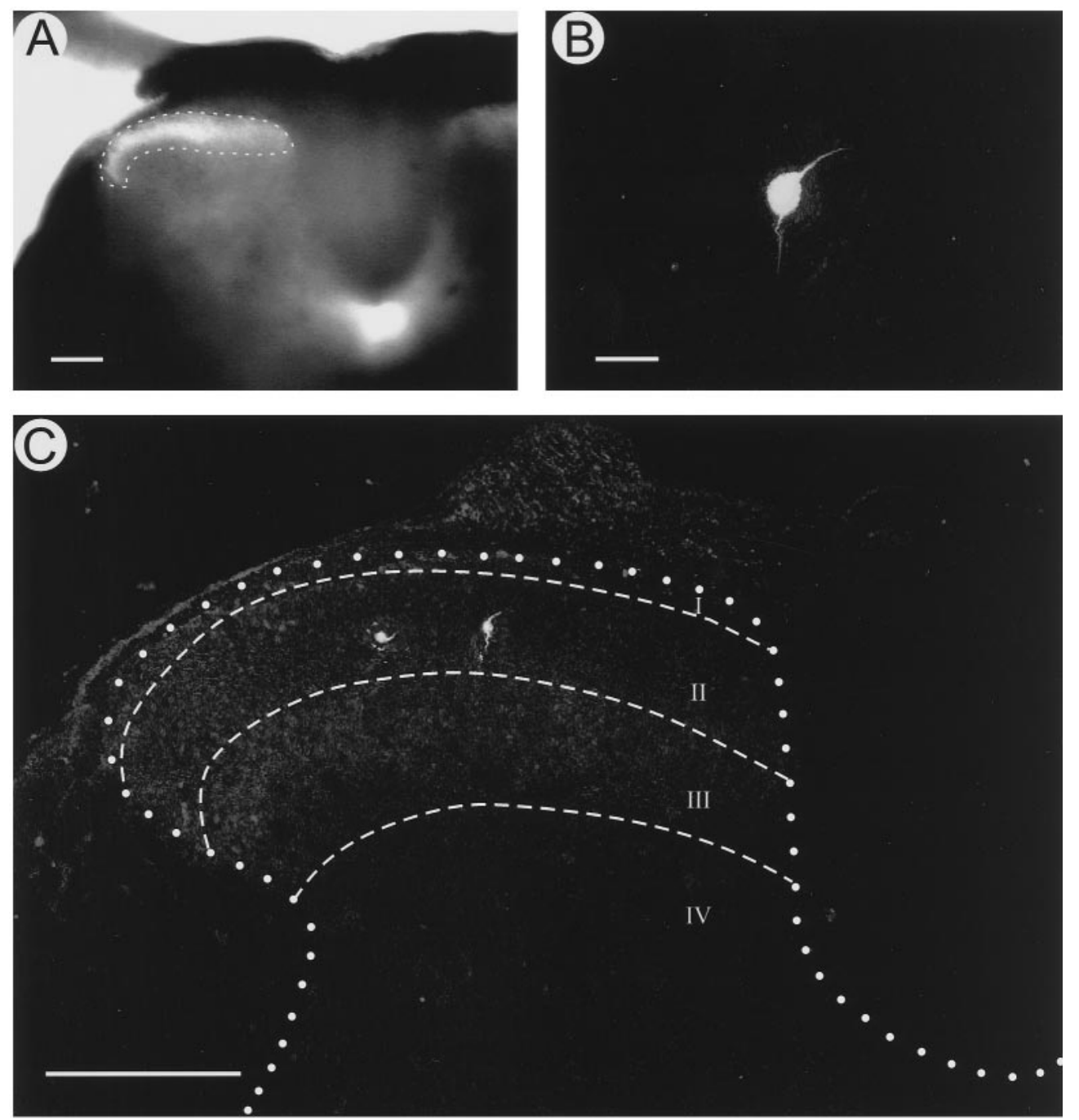

Figure 1. Identification of dorsal horn neurons in spinal cord slices. $A$, Photomicrograph of the slice preparation from normal rat showing that the SG can be identified as a translucent band in the dorsal area (dashed area). $B$, A representative lamina II neuron injected with Lucifer yellow. $C$, A lowpower photomicrograph of a slice from normal rat showing lamina II neurons filled with Lucifer yellow. Scale bars: $A, C, 250 \mu \mathrm{m} ; B, 20 \mu \mathrm{m}$.

\section{MATERIALS AND METHODS}

Surgical procedures. To induce nerve section and neuroma formation, female Sprague Dawley rats (120-180 gm, 6-8 weeks of age) were anesthetized with ketamine $(75 \mathrm{mg} / \mathrm{kg}$, i.p.) and xylazine $(10 \mathrm{mg} / \mathrm{kg}$, i.p.), and their sciatic nerves were exposed at the level of piriform tendon. The nerve was ligated with silk 4.0 suture (Ethicon, Somerville, $\mathrm{NJ}$ ) and cut distal to the suture. After surgery, the overlying skin and muscles were sutured, and the wound was treated with Betadine (Purdue Frederick, Norwalk, CT) to prevent infection. Recovery was uneventful in all cases. Unoperated animals were used as controls.

Slice preparation. Three weeks after axotomy, L4 and L5 spinal cord slices were prepared for electrophysiological and histological studies. Rats $(170-220 \mathrm{gm})$ were anesthetized with ketamine $(75 \mathrm{mg} / \mathrm{kg}$, i.p.) and xylazine $(10 \mathrm{mg} / \mathrm{kg}$, i.p.). Inspection of the sciatic nerve indicated a bulbous enlargement characteristic of a neuroma (Kocsis et al., 1984). A lumbar laminectomy was performed, and a $2.0 \mathrm{~cm}$ length of spinal cord with attached dorsal root was excised. The spinal cord was removed and placed in ice-cold oxygenated $\left(95 \% \mathrm{O}_{2}\right.$ and $\left.5 \% \mathrm{CO}_{2}\right)$ dissecting solution modified to prevent cytotoxic edema (no sodium) and calcium-induced cell death (low calcium) (in mM: choline chloride 130, choline bicarbonate 20, $\mathrm{KCl} 5.0, \mathrm{MgCl}_{2} 2.0, \mathrm{CaCl}_{2} 0.5, \mathrm{KH}_{2} \mathrm{PO}_{4} 1.2$, and dextrose 10). After removal of the dura mater, all ventral and dorsal roots, with the exception of the L4 or L5 dorsal root on right side, were cut near the root entry zone. The spinal cord was placed in an agar block and mounted on the stage of a vibratome using cyanoacrylate. A few transverse slices $(400-600 \mu \mathrm{m})$ that retained the attached dorsal roots were cut on a vibratome. The slices for electrophysiological study were transferred to an incubation chamber perfused with modified Krebs' solution (in mM: $\mathrm{NaCl}$ 124, $\mathrm{KCl} 3.0, \mathrm{MgCl}_{2} 2.0, \mathrm{CaCl}_{2}$ 2.0, $\mathrm{NaH}_{2} \mathrm{CO}_{3}$ 26, $\mathrm{NaHPO}_{4}$ 1.3, and dextrose 10 ) bubbled with $95 \% \mathrm{O}_{2}$ and $5 \% \mathrm{CO}_{2}$ at $32^{\circ} \mathrm{C}$ for recovery. After incubation for at least an hour, each slice was placed in an interface-type recording chamber and superfused continuously with the modified Krebs' solution at a drip rate of $3.0-4.0 \mathrm{ml} / \mathrm{min}$ at $35^{\circ} \mathrm{C}$. The slices used for histological study were placed in the same ice-cold Krebs' solution.

Electrophysiological recording. Conventional electrophysiological techniques were used for extracellular and intracellular recording from dorsal horn, including substantia gelatinosa (SG) cells. With transillumination under a dissecting microscope, the SG was distinguishable as a translucent band in the superficial dorsal horn (Fig. $1 A$ ), although it was difficult to discern with certainty the border between laminae I and II and the border between laminae III and IV. After recording, the accurate location of recorded sites was confirmed by extracellular injection of Fast green FCF (Sigma, St. Louis, MO) or intracellular injection of Lucifer yellow CH (Sigma). Intrasomatic injection of Lucifer yellow showed that neurons impaled in translucent band of a slice were located in the lamina II (Fig. 1B,C). These cells had morphological features and cell body diameters similar to those described previously as rat SG using Golgi (Beal and Bicknell, 1985) and horseradish peroxidase (HRP) (Woolf and Fitzgerald, 1983) labeling technique.

Orthodromic stimulation of attached dorsal roots, which had a length of $8-15 \mathrm{~mm}$, was achieved with concentric stainless-steel electrodes (outer diameter of inner and outer electrodes, 25 and $150 \mu \mathrm{m}$, respectively; Rhodes Medical Institute, Woodland Hills, CA). To determine threshold properties for $\mathrm{A} \alpha / \beta, \mathrm{A} \delta$, and $\mathrm{C}$ fibers, dorsal roots near the dorsal root entry zone in some slices were isolated, and compound action potentials (CAPs) were recorded with suction electrodes (Fig. 2A,B). FPs were recorded in the dorsal horn (laminae I-IV) with glass micro- 


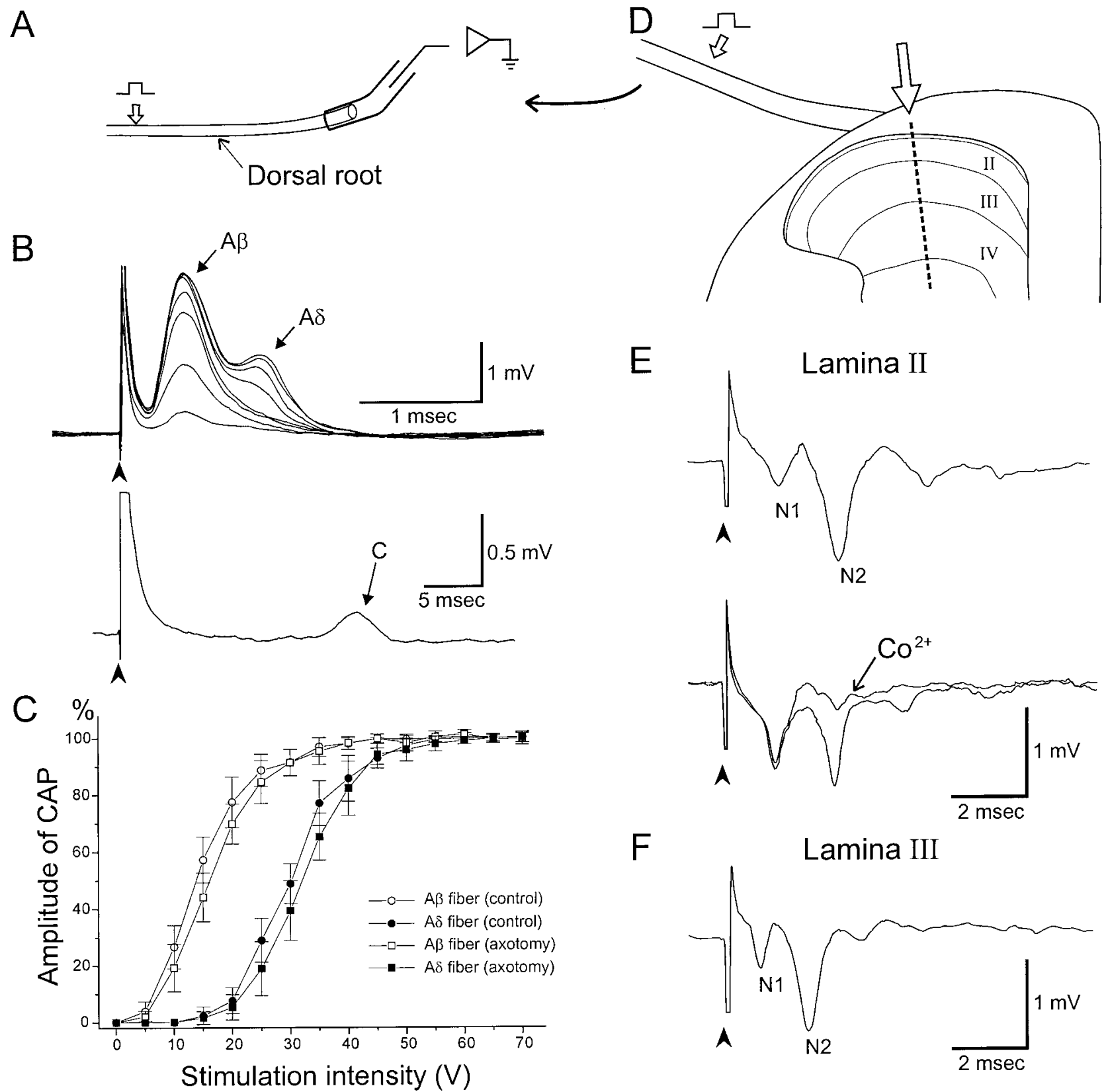

Figure 2. A, Dorsal roots were isolated and CAPs were recorded with suction electrodes. $B$, Top, Representative CAPs from A $\beta$ and A $\delta$ fibers evoked at graded stimulus intensities, 5-50 V (duration, $100 \mu \mathrm{sec}$ ). Bottom, Representative CAPs from C fibers evoked at a stimulus intensity of $80 \mathrm{~V}$ (duration, $500 \mu \mathrm{sec}$ ). The threshold intensities for $\mathrm{A} \beta, \mathrm{A} \delta$, and $\mathrm{C}$ fibers were 5,16 , and $65 \mathrm{~V}$, respectively. Estimated conduction velocities for $\mathrm{A} \beta, \mathrm{A} \delta$, and $\mathrm{C}$ fibers were $25.0,6.5$, and $0.8 \mathrm{~m} / \mathrm{sec}$, respectively. $C$, The stimulus-response relationship of A $\beta$ and A $\delta$ CAPs in normal rats $(n=5)$ and axotomized rats $(n=$ 6). $D$, FPs were recorded from dorsal horn (laminae I-IV) in rat spinal cord slice preparation. The FPs elicited by stimulation of the dorsal root were recorded at $50 \mu \mathrm{m}$ increments, as indicated by the dotted line (arrow). E, FPs recorded in lamina II. F, FPs recorded in lamina III. The FPs recorded in laminae II and III consisted of two prominent negative potentials: an initial low-amplitude negativity (N1) followed by a larger negativity (N2). A third small negative potential was seen in lamina II. In the bottom of E, FPs before and after perfusion of Krebs' solution containing 5 mM Co ${ }^{2+}$ were superimposed for comparison.

electrodes (DC resistance, 8-15 $\mathrm{M} \Omega$ ) filled with $1 \mathrm{M} \mathrm{NaCl}$ solution. In most cases, the site of the maximal FP was located in lamina II, including the SG. The FPs were recorded at $50 \mu \mathrm{m}$ increments from the dorsal horn surface to lamina IV (Fig. $2 D$ ). The depth of each recording site was $200 \mu \mathrm{m}$ below the cut-surface. Intracellular recordings were obtained from dorsal horn (laminae II-III) neuron somata using glass microelectrodes (DC resistance, $100-180 \mathrm{M} \Omega$ ) filled with $3 \mathrm{~m}$ potassium acetate and $0.01 \mathrm{M} \mathrm{KCl}$. Impaled neurons were studied only if the recorded resting membrane potential was less than $-55 \mathrm{mV}$ and suprathreshold stimulation of dorsal root produced large-amplitude short-duration spikes, which are characteristic of intrasomatic recording in lamina II (Yoshimura and Jessell, 1989) and lamina III (Gerber et al., 1991). The electrical signals were fed into a computer using commercial software (pClamp; Axon Instruments, Foster City, CA), through an analog-todigital converter for on-line processing and into a VCR with a digitizing unit for off-line processing. A low-pass filter was used for the extracellular recordings.

Histological examination. HRP procedures were used to look for termination of central afferents (Kocsis et al., 1984). Dorsal root cut ends were exposed 6 hr to Texas Red-conjugated HRP (Sigma) (15\% Ringer's 
Table 1. Compound action potentials in dorsal roots

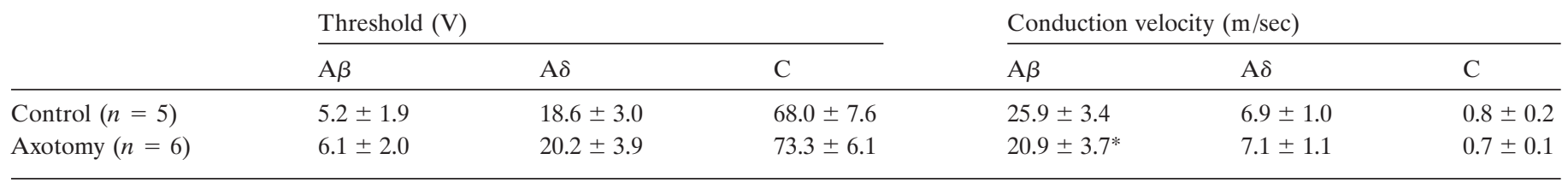

Data are presented as mean $\pm \mathrm{SD}$.

$p$ values were calculated using the Student's $t$ test; * $p<0.05$ in comparison of axotomized versus control dorsal roots.

Table 2. Field potentials in laminae II-III

Latency of negative peak $(\mathrm{msec})$

\begin{tabular}{|c|c|c|c|c|c|c|}
\hline \multirow[b]{2}{*}{ Recording site } & \multicolumn{3}{|c|}{ Latency of negative peak (msec) } & \multicolumn{3}{|c|}{ Peak amplitude (mV) } \\
\hline & N1 & $\mathrm{N} 2$ & N3 & N1 & $\mathrm{N} 2$ & N3 \\
\hline \multicolumn{7}{|l|}{ Control } \\
\hline Lamina II $(n=15)$ & $1.3 \pm 0.1$ & $2.7 \pm 0.4$ & $5.0 \pm 0.6$ & $0.5 \pm 0.3$ & $1.1 \pm 0.3$ & $0.6 \pm 0.2$ \\
\hline Lamina III $(n=15)$ & $1.0 \pm 0.2$ & $1.7 \pm 0.2$ & - & $0.4 \pm 0.2$ & $1.0 \pm 0.2$ & - \\
\hline \multicolumn{7}{|l|}{ Axotomy } \\
\hline Lamina II $(n=12)$ & $1.1 \pm 0.1$ & $2.1 \pm 0.4^{* *}$ & $4.3 \pm 0.6^{*}$ & $0.5 \pm 0.2$ & $1.1 \pm 0.2$ & $1.0 \pm 0.2^{* * *}$ \\
\hline Lamina III $(n=12)$ & $0.9 \pm 0.2$ & $1.7 \pm 0.4$ & - & $0.5 \pm 0.2$ & $1.1 \pm 0.4$ & - \\
\hline
\end{tabular}

Data are presented as mean $\pm \mathrm{SD}$.

$p$ values were calculated using the Student's $t$ test; ${ }^{*} p<0.05 ;{ }^{*} p<0.01 ; * * *<0.001$; in comparison of axotomized versus control slices.

solution at $\left.5^{\circ} \mathrm{C}\right)$. The slice preparation was then rinsed and stored $48-72$ $\mathrm{hr}$ in Ringer's solution $\left(4-7^{\circ} \mathrm{C}\right)$ before paraformaldehyde (4\%) fixation. Each slice was whole-mounted on a slide glass and observed under a confocal laser-scanning head (LSM-410; Zeiss, Thornwood, NY) with a $10 \times$ objective (Achrostigmat; Zeiss). The light source for the confocal microscope was a multi-line argon ion laser (exciting wavelength, 568 $\mathrm{nm}$ ). Each image is the product of 16 -fold frame averaging. A series of images was taken through the entire depth of the labeled area, and the images were stored on an optical disk. The entire course of extensions of afferent fibers was traced on the cumulative images at $3 \mu \mathrm{m}$ intervals.

\section{RESULTS}

\section{Primary afferent threshold and conduction velocity}

Primary afferents could be divided into three groups corresponding to $\mathrm{A} \alpha / \beta, \mathrm{A} \delta$, and $\mathrm{C}$ fibers, on the basis of threshold and conduction velocity extracellularly recorded (CAPs) from the dorsal root (Fig. 2A,B). Fiber responses are shown in Figure $2 B$ to various stimulus intensities; plots of these responses $(n=5)$ are shown in Figure $2 C$ before and after sciatic nerve section and ligation. Responses elicited at low-threshold $(<20 \mathrm{~V})$ stimulation intensities were $\mathrm{A} \beta$-mediated; these responses had maximum amplitude at $40 \mathrm{~V}$. Responses elicited at high-threshold $(>40 \mathrm{~V})$ stimulation intensities were $\mathrm{A} \delta$ - or $\mathrm{C}$ fiber-mediated. At stimulus intensities between 20 and $40 \mathrm{~V}$ it was difficult to differentiate unambiguously $\mathrm{A} \beta$ or $\mathrm{A} \delta$ fiber responses (Fig. $2 C$ ). Table 1 shows the stimulation thresholds and conduction velocities for the $\mathrm{A} \beta$, $\mathrm{A} \delta$, and $\mathrm{C}$ fibers recorded in dorsal roots from normal and rats with axotomized sciatic nerve. The stimulation threshold did not change before and after axotomy, but the conduction velocities for A $\beta$ fibers were reduced after axotomy from $25.9 \pm 3.4 \mathrm{~m} / \mathrm{sec}$ $(n=5)$ to $20.9 \pm 3.7 \mathrm{~m} / \mathrm{sec}(n=6 ; p<0.05)$ (Table 1$)$. The values obtained for threshold and conduction velocity are in agreement with those found in earlier studies in vivo before and after axotomy (Harper and Lawson, 1985; Devor and GovrinLippmann, 1986; Villiere and McLachlan, 1996).

\section{Field potential profiles elicited by dorsal root stimulation}

FPs in the dorsal horn elicited by dorsal root stimulation were recorded in control slices $(n=15)$ and slices from rats with axotomized sciatic nerves $(n=12)$. In the control slices, the FPs recorded in lamina II consisted of two prominent negative potentials: an initial low-amplitude negativity (N1) followed by a larger negative potential (N2) (Fig. 2E; see Table 2 for latencies). These early potentials were followed by variable low-amplitude negativities. The initial potential was not blocked by perfusion of Krebs' solution containing $5 \mathrm{mM} \mathrm{Co}^{2+}$ to block $\mathrm{Ca}^{2+}$ currents and synaptic transmission, but subsequent negativities were blocked by $\mathrm{Ca}^{2+}$ channel blockade. This indicates that the initial potential was generated by afferent fibers (i.e., presynaptic volley) and the subsequent potential by synaptic activity.

The FPs recorded in lamina III also consisted of two welldefined negative potentials with an initial low-amplitude negativity followed by a second larger negativity (Fig. $2 F$ ). The latencies of the first and second negativities recorded in lamina III were shorter than those in lamina II (Fig. 2E; Table 2). These observations indicate that lamina III neurons receive inputs from afferent fibers with faster conduction velocities, i.e., larger axon diameters. This is in agreement with anatomical studies showing that $\mathrm{A} \delta$ and $\mathrm{C}$ fibers terminate primarily in lamina II, and $\mathrm{A} \beta$ fibers in lamina III (Woolf et al., 1992; Shortland and Woolf, 1993).

FPs recorded in a control and an axotomized ( 3 weeks) slice at various depths can be compared in Figure 3. N1 and N2 recorded in lamina II in the axotomized slice had amplitudes similar to controls. However, the latency of N2 recorded in lamina II after axotomy was shorter (Fig. 3B, Table 2). Another difference in lamina II FPs after axotomy was the appearance of largeamplitude late negativities following N2, as can be seen in Figure $3 A$ (right column, dots). These prominent negativities were recorded in all axotomized slices $(n=12)$. These results suggest that lamina II neurons receive inputs from afferent fibers with faster conduction velocities after axotomy. The FPs recorded in lamina III were largely unchanged after axotomy, although conduction velocity of dorsal root $\mathrm{A} \beta$ fibers was reduced (Table 1); $\mathrm{N} 1$ and N2 had similar latencies and amplitudes, and no prominent late negativities were observed (Table 2). 

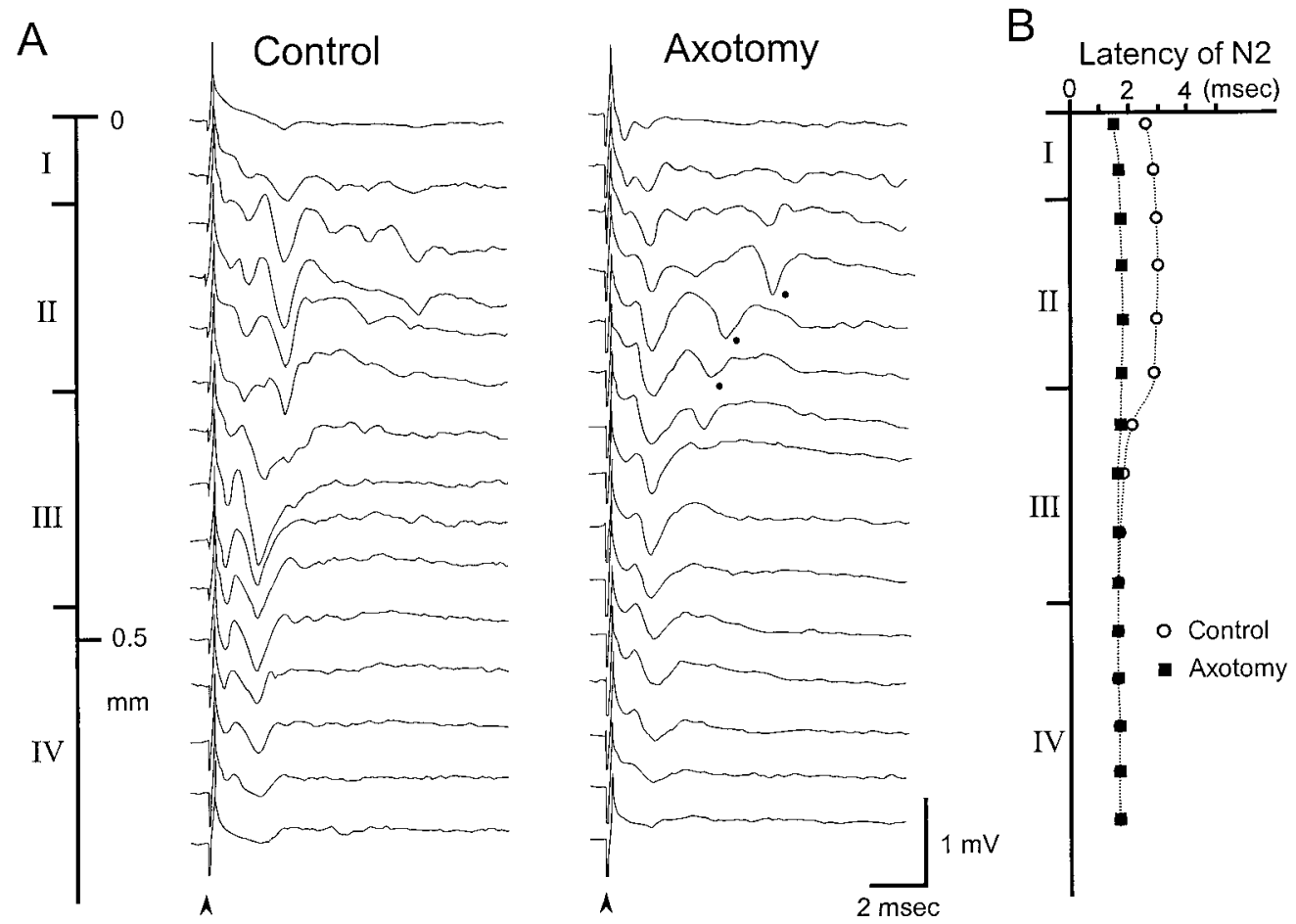

Figure 3. FPs recorded in dorsal horn (laminae I-IV) by dorsal root stimulation. A, FPs in control slice (left) and axotomized slice (right) are averages for five stimulation trials. The recording depth and corresponding dorsal horn laminae are indicated to the left. Dots show large-amplitude late negativities after $\mathrm{N} 2$ in axotomized slice. $B$, Latencies of the second large negative peak that corresponds to the postsynaptic currents were plotted at $50 \mu \mathrm{m}$ increments along dorsal horn laminae. The latencies of $\mathrm{N} 2$ in the axotomized slices are reduced in laminae I and II.

\section{Membrane properties of dorsal horn neurons}

Stable intracellular recordings were obtained from 72 dorsal horn neurons (laminae II-III) in slices $(n=25)$ from 18 normal rats and 83 dorsal horn neurons in slices $(n=31)$ from 20 rats with axotomized sciatic nerve that received EPSPs elicited by stimulation of the dorsal roots. Nine neurons from normal slices and 14 neurons from axotomized slices exhibited resting membrane potentials less than $-55 \mathrm{mV}$, but did not respond to dorsal root stimulation. The average membrane potentials of laminae II and III neurons recorded from normal slices were $-62.7 \pm 5.1 \mathrm{mV}$ $(n=40)$ and $-63.0 \pm 5.0 \mathrm{mV}(n=32)$, respectively, and in axotomized slices they were $-63.2 \pm 5.7 \mathrm{mV}(n=57)$ and $-62.6 \pm 4.9 \mathrm{mV}(n=26)$, respectively. Mean input resistances of laminae II and III were $243 \pm 40.9 \mathrm{M} \Omega(n=12)$ and $232 \pm 38.4$ $\mathrm{M} \Omega(n=10)$, respectively, and in axotomized slices they were $246 \pm 31.1 \mathrm{mV}(n=23)$ and $226 \pm 25.1 \mathrm{mV}(n=9)$, respectively. No significant differences in these membrane characteristics were detected between neurons recorded from control and axotomized slices.

\section{Primary afferent evoked EPSPs in dorsal horn neurons}

In control slices, EPSPs were recorded from 40 neurons in lamina II and 32 neurons in lamina III evoked by dorsal root stimulation. Conduction velocities of afferents could be calculated from EPSP latency onset recordings obtained from lamina II dorsal horn neurons after two-point root stimulation (Fig. $4 A$ ). The conduction velocities were $3.6 \pm 1.9 \mathrm{~m} / \mathrm{sec}(n=5)$ and $31 \pm 12 \mathrm{~m} / \mathrm{sec}$ $(n=3)$ for lamina II and lamina III neurons, respectively. These values suggest that $\mathrm{A} \delta$ (range, $2-8 \mathrm{~m} / \mathrm{sec}$ ) and $\mathrm{A} \beta$ (range, 17-60 $\mathrm{m} / \mathrm{sec}$ ) fibers mediate afferent input to lamina II and lamina III, respectively (Shortland and Woolf, 1993).

Several lines of evidence indicate that the initial EPSPs in lamina II elicited by single stimuli of the dorsal root were monosynaptic in origin. First, the latencies to onset were invariant to multiple stimulus presentation (Fig. 4B1,B2). Second, the latency of the EPSPs remained constant when the stimulus intensity was increased in a graded manner from subthreshold to supramaximal intensities (Fig. 4D). Moreover, the EPSPs had invariant latencies during repetitive high frequency $(20 \mathrm{~Hz})$ stimulation $(n=6$; Fig. $4 C$ ). Monosynaptic EPSPs recorded from lamina III neurons had a shorter latency and a faster initial slope than those from lamina II neurons (Fig. 4E,F, Table 3). Some neurons of lamina III displayed late depolarizing potentials with varied amplitudes after the fast monosynaptic EPSP, suggesting late polysynaptic activity (Fig. $4 F$ ). Moreover, some laminae II and III neurons had variant latencies of the early EPSP, suggesting a polysynaptic origin (Fig. 4G).

The threshold for activation of monosynaptic EPSPs in laminae II and III neurons in control slices was different; lamina II neurons were high-threshold, and lamina III neurons were lowthreshold (Table 3 ). In addition to differences in EPSP activation threshold, lamina II neurons had smaller EPSP amplitudes, less steep slopes of the rising phase of the EPSP, and longer latencies than EPSPs from lamina III neurons (Table 3). Together these results indicate that in control slices low-threshold EPSPs evoked by fast-conducting afferents are prevalent in lamina III, and high-threshold EPSPs evoked by slowly conducting afferents are characteristic of lamina II neurons.

\section{Changes in EPSP properties after axotomy and neuroma formation}

There were a number of changes observed in EPSPs recorded from lamina II neurons, but not of lamina III neurons after axotomy. A prominent difference was the emergence of low- 
A

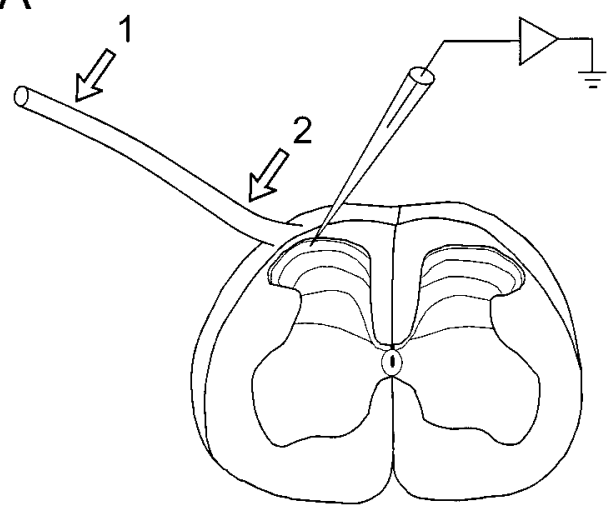

C

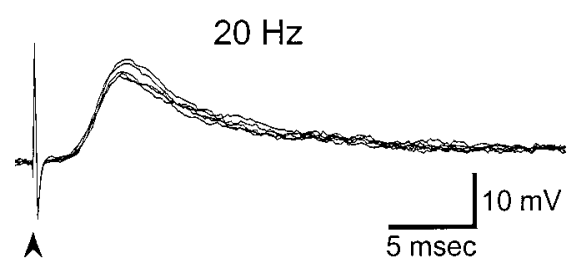

B

B
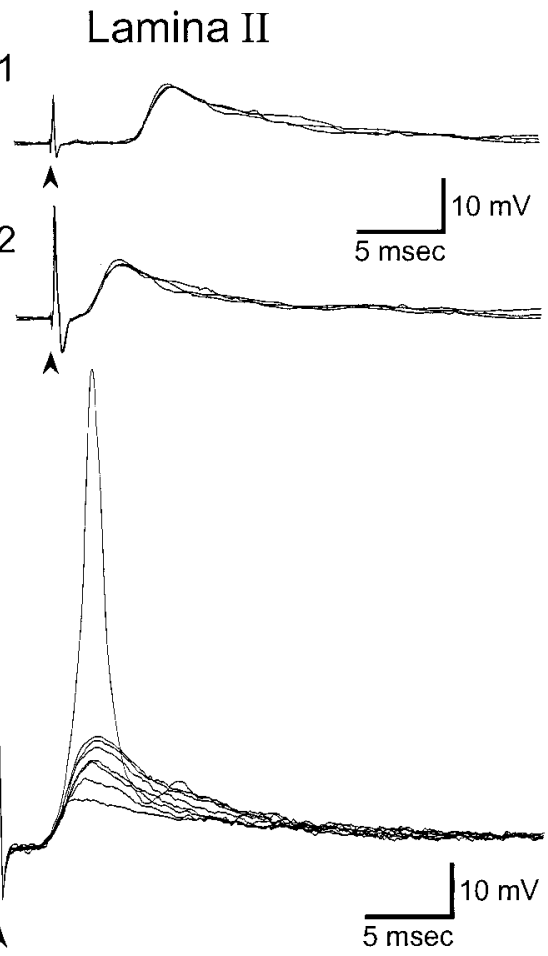
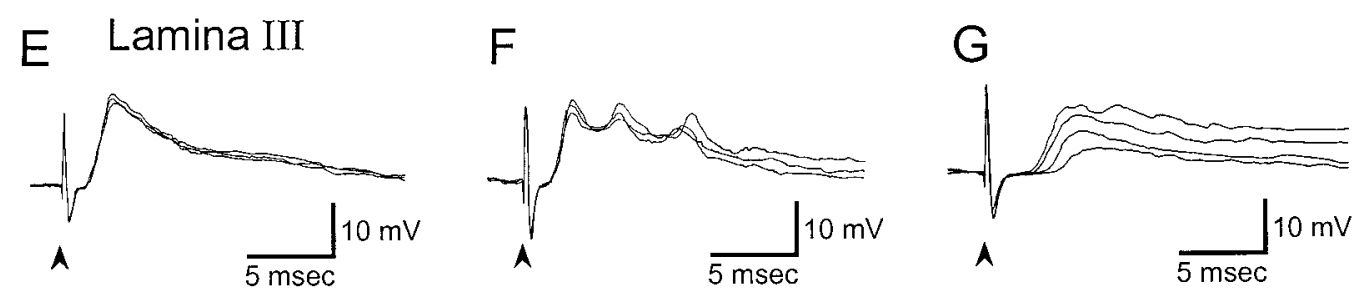

Figure 4. A, Schematic arrangement for intracellular recording and dorsal root stimulation. The dorsal root was stimulated by concentric electrodes positioned at 1 and 2. B1, B2, High-threshold monosynaptic EPSPs recorded from a lamina II neuron evoked by single stimuli applied at two different points of the dorsal root $(A 1$ and $A 2)$ in control slices. The difference of EPSP latency onsets permitted calculation of the conduction velocity of fibers responsible for the evoked EPSP (calculated conduction velocity, $3.5 \mathrm{~m} / \mathrm{sec}$ ). $C$, Another representative high-threshold monosynaptic EPSP had constant latencies during $20 \mathrm{~Hz}$ repetitive stimulation. $D$, The latency of the EPSPs remained constant with an increase in the stimulus intensity. Suprathreshold afferent stimulation produced large-amplitude short-duration spikes. $E-G$, Low-threshold monosynaptic and polysynaptic EPSPs recorded intracellularly in lamina III of control slices. EPSPs recorded from the neuron in lamina III had a shorter latency and a faster initial slope than those from the neuron in lamina II $(E, F)$. EPSPs recorded from some neurons in lamina III consist of a short-latency fast monosynaptic EPSP followed by a few fast and slow polysynaptic components of varied amplitude $(F)$. In some neurons the poststimulus latencies were variable $(G)$. The amplitude and duration of EPSPs was usually augmented by an increase in stimulus intensity.

threshold monosynaptic EPSPs in lamina II after axotomy. Whereas $73 \%$ (29 of 40) of lamina II neurons in control slices exhibited high-threshold monosynaptic or polysynaptic EPSPs, and $18 \%$ (7 of 40) exhibited low-threshold EPSPs, 54\% (31 of 57) of lamina II neurons exhibited low-threshold monosynaptic or polysynaptic EPSPs after axotomy (Table 3). The high-threshold monosynaptic EPSPs in lamina II after axotomy had amplitudes, slopes, and onset latencies similar to controls. In contrast, the low-threshold monosynaptic EPSPs that emerged in lamina II after axotomy had characteristics similar to those recorded in lamina III neurons of control slices (Fig. 5A, Table 2). Typical of the low-threshold responses in lamina II after axotomy was the ability to maintain a stable onset with $20 \mathrm{~Hz}$ repetitive stimulation, indicative of monosynaptic inputs in the dorsal horn (Yoshimura and Jessell, 1990). In three of the monosynaptic responses evoked by low-threshold inputs in lamina II after axotomy, the conduction velocity could be accurately calculated from two-point root stimulation, and they were in the $\mathrm{A} \beta$ fiber range $(26 \pm 4.4 \mathrm{~m} / \mathrm{sec}$ ) (Fig. $5 B)$. Moreover, multiple component EPSPs with late activity (Fig. $5 C$ ) and polysynaptic EPSPs with variant onset latencies to even low-frequency stimulation (Fig. $5 D$ ) were observed in lamina II after axotomy. These properties were similar to low-threshold EPSPs recorded in lamina III of control slices and were rarely observed in lamina II neurons of control slices (Table 3).

Graphs showing the pattern of EPSP threshold in laminae II and III before and after axotomy are shown in Figure 6, $A$ and $B$, respectively. It is clear that axotomy increased the number of lamina II neurons responding to low-threshold monosynaptic or polysynaptic inputs. Figure $6 C$ shows the spatial distribution of neurons receiving EPSPs driven by different types of afferent fibers in control and axotomized slices. The distribution of neurons receiving low-threshold EPSPs in lamina II increased after axotomy, as did the number of low-threshold polysynaptic inputs. 


\begin{tabular}{|c|c|c|c|c|c|c|}
\hline & Type of EPSPs & $n=$ & $\begin{array}{l}\text { Latency } \\
(\mathrm{msec})\end{array}$ & $\begin{array}{l}\text { Peak amplitude } \\
(\mathrm{mV})\end{array}$ & $\begin{array}{l}\text { EPSP slope } \\
(\mathrm{dV} / \mathrm{dT})\end{array}$ & Number of peaks \\
\hline \multicolumn{7}{|l|}{ Lamina II } \\
\hline \multirow[t]{4}{*}{ Control } & Low-threshold mono & 1 & 2.1 & 14.5 & 8.5 & 1.0 \\
\hline & Low-threshold poly & 6 & - & $13.7 \pm 2.8$ & - & $2.8 \pm 1.2$ \\
\hline & High-threshold mono & 27 & $2.4 \pm 1.2$ & $11.8 \pm 3.7$ & $6.3 \pm 2.7$ & $1.2 \pm 0.4$ \\
\hline & High-threshold poly & 2 & - & $16.1 \pm 2.9$ & - & $2.5 \pm 0.7$ \\
\hline \multirow[t]{4}{*}{ Axotomy } & Low-threshold mono & 13 & $1.9 \pm 0.5$ & $15.5 \pm 4.0^{* *}$ & $11.7 \pm 3.6^{* * *}$ & $2.3 \pm 1.4^{*}$ \\
\hline & Low-threshold poly & 18 & - & $20.3 \pm 6.6$ & - & $2.9 \pm 1.0$ \\
\hline & High-threshold mono & 19 & $2.5 \pm 1.1$ & $11.9 \pm 4.3$ & $7.1 \pm 2.8$ & $1.4 \pm 0.5$ \\
\hline & High-threshold poly & 2 & - & $17.6 \pm 3.9$ & - & $2.5 \pm 0.7$ \\
\hline \multicolumn{7}{|l|}{ Lamina III } \\
\hline \multirow[t]{3}{*}{ Control } & Low-threshold mono & 16 & $1.8 \pm 0.3$ & $17.5 \pm 2.6$ & $14.0 \pm 2.2$ & $2.9 \pm 1.5$ \\
\hline & Low-threshold poly & 7 & - & $17.3 \pm 2.6$ & - & $2.4 \pm 0.5$ \\
\hline & High-threshold poly & 3 & - & $18.7 \pm 2.2$ & - & $2.3 \pm 0.6$ \\
\hline \multirow[t]{3}{*}{ Axotomy } & Low-threshold mono & 15 & $1.7 \pm 0.3$ & $17.1 \pm 1.7$ & $12.5 \pm 2.6$ & $2.6 \pm 1.6$ \\
\hline & Low-threshold poly & 6 & - & $16.4 \pm 2.6$ & - & $2.8 \pm 0.8$ \\
\hline & High-threshold poly & 1 & - & 16.2 & - & 2.0 \\
\hline
\end{tabular}

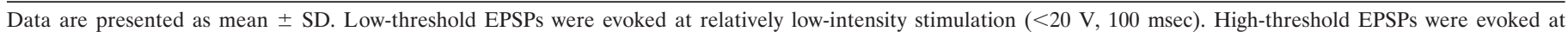

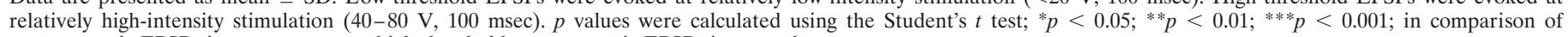
monosynaptic EPSPs in axotomy versus high-threshold monosynaptic EPSPs in control.

\section{Projection of primary afferent fibers in the dorsal horn}

The arborization pattern of dorsal horn afferents was studied by Texas Red-conjugated HRP applied to the dorsal root (see Materials and Methods). In eight control slices, it was possible to follow the axonal trajectory of labeled afferents within the dorsal horn. We observed five central afferents with terminal arbors that resembled the flame-shaped appearance that is characteristic of hair follicle A $\beta$ afferents (Brown et al., 1977; Woolf, 1987; Shortland et al., 1989). It has been found that the central terminals of $\mathrm{A} \beta$ afferents with flame-shaped appearance sprout into laminae I-II after axotomy (Woolf et al., 1992; Shortland and Woolf, 1993). The appearance of the terminal arbors from control intact afferent fibers is shown in Figure $7 A$. These afferents had a U-shaped curving collateral axon, and the terminations of the arbors were located within laminae III-IV. None of their terminal arbors penetrated lamina II (Fig. 7A1,A2, arrowheads).

After axotomy $(n=9)$, we observed six central afferents with terminal arbors that resembled the flame-shaped appearance and were presumed to be hair follicle $\mathrm{A} \beta$ afferents. In three of the six flamed-shaped-like afferents, the morphology of the individual axon terminals was similar to control. However, the laminar termination sites of some axotomized flamed-shaped-like afferents extended into lamina II (Fig. 7B1,B2, arrowheads). Seventeen collateral arbors from three different axotomized preparations were observed extending into lamina II, whereas none $(n=5)$ did so in the controls.

\section{DISCUSSION}

In this study we used extracellular and intracellular recording techniques to examine synaptic inputs to the dorsal horns after peripheral nerve section and ligation where a neuroma was formed. Our results indicate a reorganization of peripheral afferent inputs to the dorsal horn characterized by a reduction in high-threshold, slowly conducting inputs to lamina II and an increase in low-threshold fast-conducting inputs characteristic of $\mathrm{A} \beta$ fibers to lamina II. No changes in synaptic transmission were observed in deeper laminae (i.e., III and IV).

\section{Peripheral and central sprouting after peripheral nerve section}

After peripheral nerve section, axonal sprouting occurs in both the central and peripheral processes of afferent neurons. When a peripheral nerve is sectioned but allowed to regenerate to a peripheral target, regeneration can be very successful; after a delay of a day or two the axons sprout and elongate through the distal segment of the peripheral nerve, and reestablish functional connections with a peripheral target (Horch, 1988; Munson et al., 1988; McMahon et al., 1989). However, if peripheral reconnections are blocked such as by a nerve ligation, the axons will sprout, but a neuroma will form at the site of injury (Kocsis et al., 1984; Ashur et al., 1987; Fried and Devor, 1988; Devor et al., 1991; Fried et al., 1991). The neuroma displays a number of pathological properties such as increased chemosensitivity and mechanosensitivity and cross-excitation (Wall and Gutnick, 1974; GovrinLippmann and Devor, 1978; Blumberg and Janig, 1982; Kocsis et al., 1984), and "spontaneous" or ectopic impulse firing (Wall and Gutnick, 1974; Govrin-Lippmann and Devor, 1978; Devor et al., 1990; Welk et al., 1990). Unlike adaptive regeneration in which axons grow back to an appropriate target and reestablish functional connections, the regenerative response of a nerve blocked from its target is maladaptive. The ectopic impulse activity has been suggested to result in pain or paresthesia (Devor et al., 1991).

Sprouting may also occur on the central domains of primary afferent fibers after peripheral nerve section. It is well established that injury to a peripheral sensory nerve can result in increased axonal sprouting in the spinal cord (Richardson and Issa, 1984; Richardson and Verge, 1987; Molander et al., 1988; McMahon and Kett-White, 1991). More recently a number of anatomical studies indicate that after nerve injury the central axonal terminals of injured afferents undergo synaptic plasticity (Woolf et al., 1992; Shortland and Woolf, 1993; Koerber et al., 1994; Tong et al., 1999). After nerve injury synaptic terminals are increased some 15 -fold in the superficial dorsal horn (SG) as observed by 


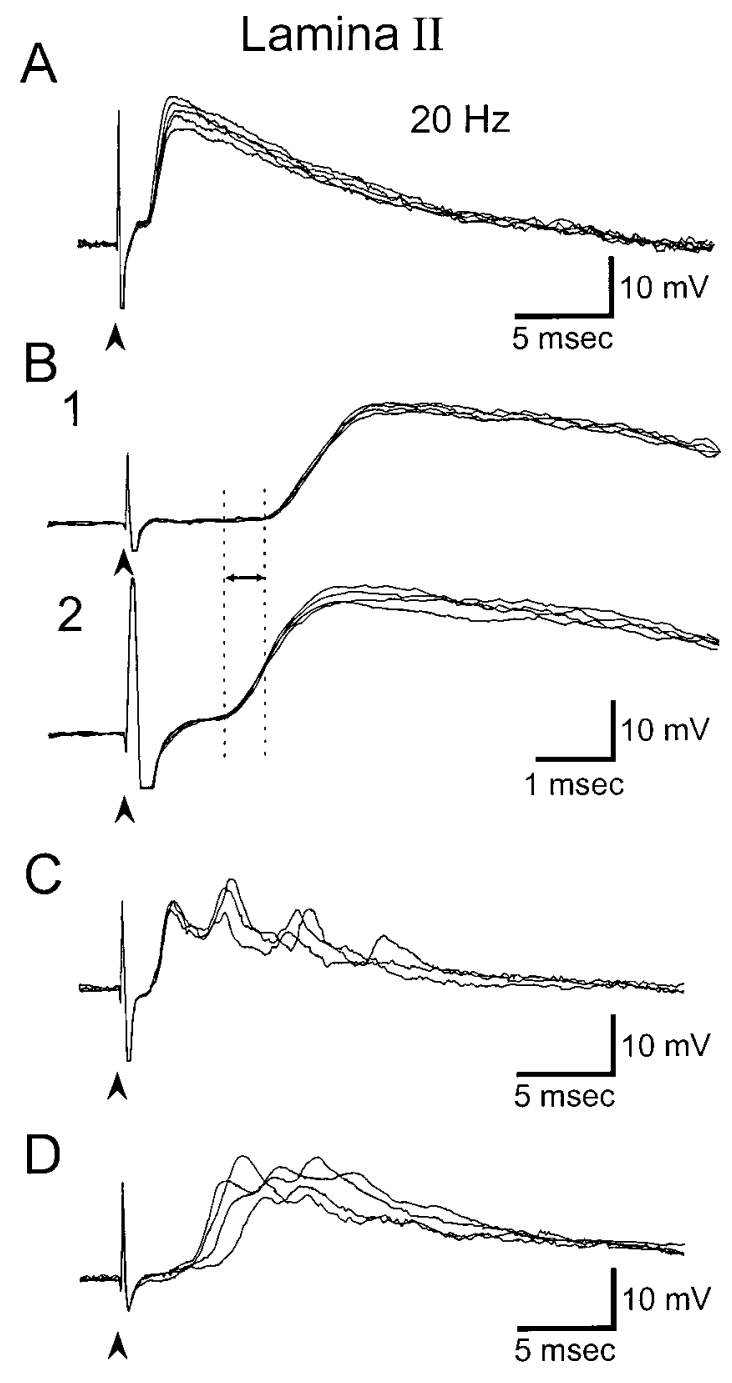

Figure 5. Low-threshold monosynaptic and polysynaptic EPSPs recorded in lamina II of axotomized slices. $A$, A representative lowthreshold monosynaptic EPSP had constant latencies during $20 \mathrm{~Hz}$ repetitive stimulation. They had shorter latencies and faster initial slopes, which were similar to those obtained from lamina III in control slices. B1, $B 2$, Single stimuli were applied at two different points of the dorsal root to calculate the conduction velocity of fibers responsible for the evoked EPSP. Conduction velocity calculated by the difference of EPSP latency onsets was $25.5 \mathrm{~m} / \mathrm{sec}$ (distance between two stimulus points, $13.5 \mathrm{~mm}$ ). $C$, In some neurons of lamina II, fast monosynaptic EPSP were followed by a few fast and slow polysynaptic components. $D$, Polysynaptic EPSPs of variable amplitude, latency, and shape were detected in lamina II.

electron microscopy (Woolf et al., 1995). Monosynaptic cord dorsum potentials (CDPs) evoked by stimulation of chronically axotomized afferents were much larger in amplitude than those evoked by stimulation of intact control afferents (Koerber et al., 1994). Moreover, a fiber stimulation of the intact sciatic nerve produces little c-fos expression in normal dorsal horn neurons, but after nerve injury such stimulation results in many labeled cells in lamina II (Molander et al., 1992). These observations suggest that synaptic inputs for postsynaptic targets increased in superficial laminae after peripheral nerve injury.

HRP tracing of axons after nerve section and neuroma formation in the present study revealed central dorsal horn afferents with several types of arborization patterns. We paid particular attention to central afferent fibers entering deep laminae (III-V) with terminal arbors having a flame-shaped appearance, which is characteristic of hair follicle afferents, i.e., A $\beta$ axons (Brown et al., 1977; Woolf, 1987; Shortland et al., 1989). Our results indicate a recurrence of these large afferents from laminae III-IV into lamina II. After axotomy, Woolf et al. (1995) observed abnormal arborization patterns and sprouting of bouton-containing terminals into superficial dorsal horn. They suggested peripheral axotomy could induce a disruption of the normal somatotopic organization and a structural reorganization of the central terminals of $\mathrm{A} \beta$ afferents, such as low-threshold mechanoreceptive afferents.

\section{Molecular reorganization of large cutaneous afferent neurons}

Cutaneous afferent neurons undergo a number of changes in the organization of their ion channels in response to axotomy. Large cutaneous afferent neurons (Honmou et al., 1994) and their axons (Kocsis et al., 1983; Honmou et al., 1994; Sakai et al., 1998) express a kinetically slow sodium channel that is not observed on muscle afferents of comparable size. After nerve injury the slow sodium currents are reduced (Rizzo et al., 1995), but when the cut ends of the nerves are treated with NGF, the reduction in slow sodium current is reduced. Moreover, more recent work indicates that the TTX-sensitive sodium currents, which have faster kinetics, display even faster repriming times, thus providing for the possibility of higher frequency discharge (Cummins and Waxman, 1997). In agreement with these biophysical observations, mRNA expression for the SNS sodium channel, which is suggested to correlate with the kinetically slow sodium current, is reduced after axotomy (Dib-Hajj et al., 1998). It is interesting that the refractory periods of cutaneous afferent axons are reduced after nerve injury (Sakai et al., 1998), possibly because of the reduction in the repriming time of the fast sodium currents. Additionally, potassium currents (sustained K current and transient A current) of large cutaneous afferents are reduced to approximately half after nerve injury (Everill and Kocsis, 1999). The large reduction in $\mathrm{K}^{+}$and slow $\mathrm{Na}^{+}$currents and the faster repriming kinetics of the TTX-sensitive fast $\mathrm{Na}^{+}$currents could provide a pathophysiological substrate to account for the facilitation of hyperexcitability of these neurons after nerve injury. The altered synaptic organization in the dorsal horn of these neurons as reported here could further exacerbate the abnormal processing of sensory information of injured afferent fibers.

\section{Electrophsyiological changes in excitatory inputs to the dorsal horn after neuroma formation}

Our electrophysiological results are in agreement with anatomical studies showing that after nerve section, terminals of $\mathrm{A} \beta$ afferent fibers sprout into superficial dorsal horn and produce aberrant synapses. We recorded direct synaptic potentials evoked by stimulation of sprouting fibers after peripheral nerve ligation. The latency of the synaptic component (N2) of the FPs recorded in lamina II shortened after axotomy and approached that of synaptic responses recorded in lamina III, which receive synaptic currents from predominately large myelinated $\mathrm{A} \beta$ afferent fibers, whereas the neurons in lamina II receive thinly myelinated (A $\delta$ ) and nonmyelinated (C) afferent fibers (Brown, 1981; Shortland et al., 1989; Brown et al., 1991; Willis and Coggeshall, 1991). Neurons in lamina II appear to receive synaptic currents from large myelinated afferent fibers after axotomy; many neurons (54\%, 31 of 57) after axotomy recorded in lamina II received low-threshold monosynaptic or polysynaptic EPSPs, whereas 7 of 40 neurons 
A Lamina II

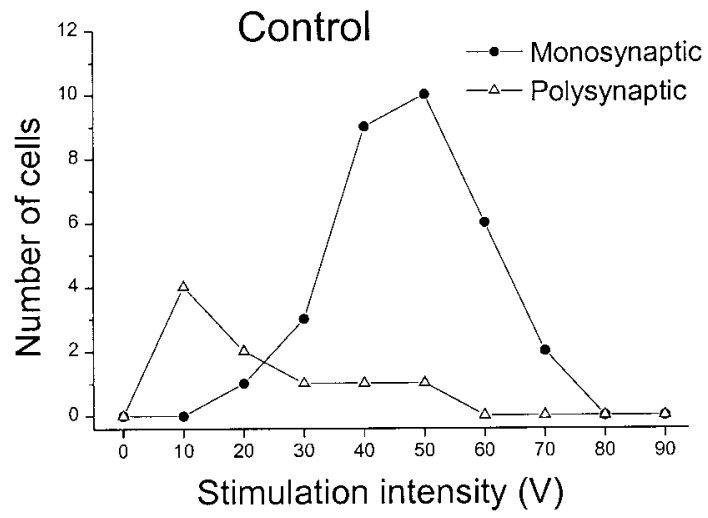

B Lamina III

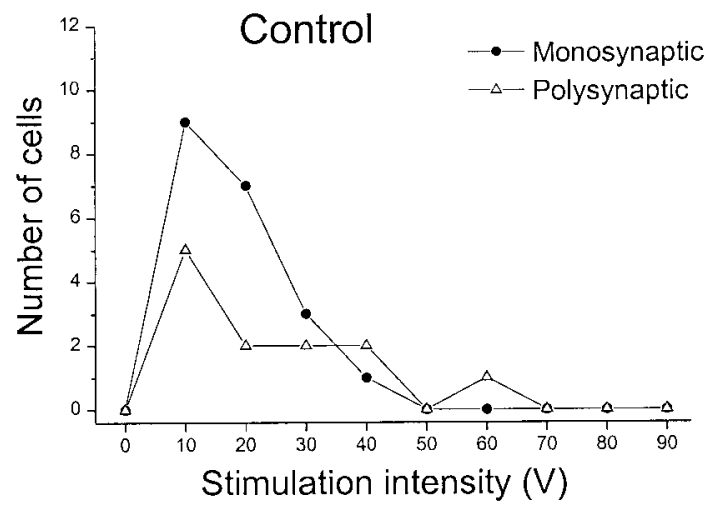

C

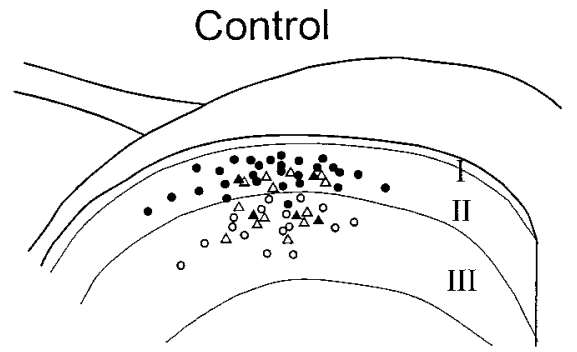

- Low-threshold (mono)

$\triangle$ Low-threshold (poly)

- High-threshold (mono)

- High-threshold (poly)
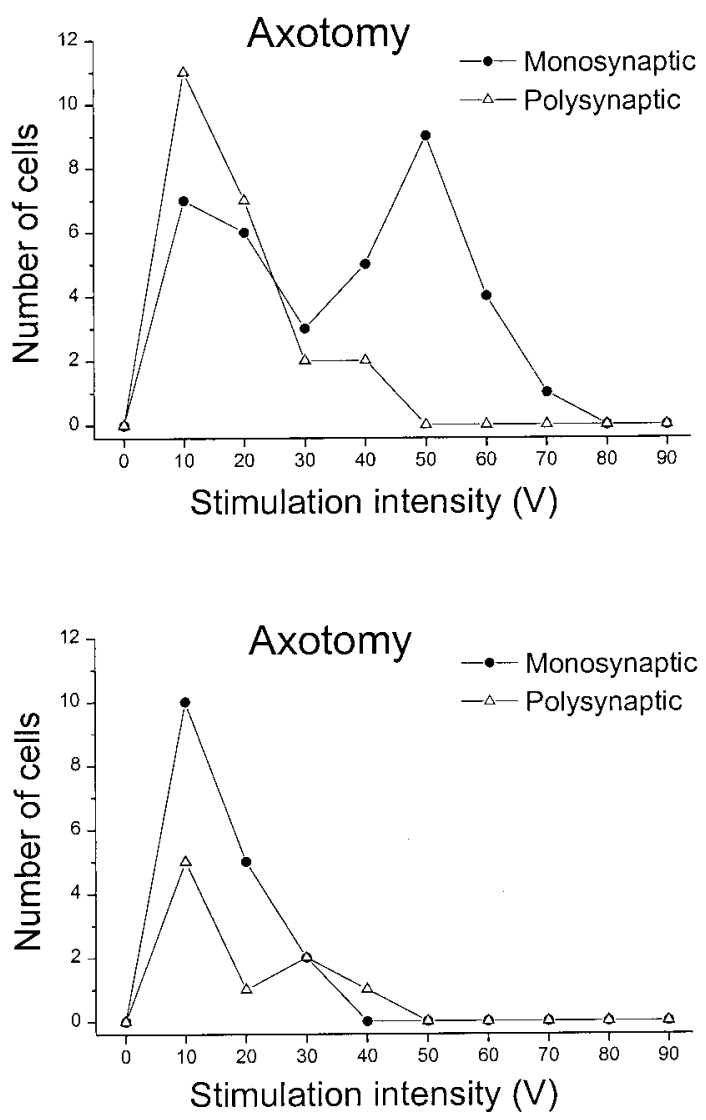

Axotomy

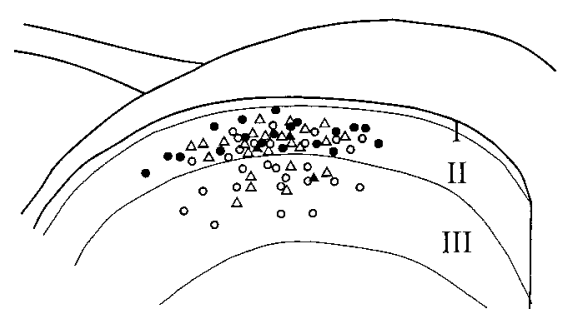

Figure 6. $A, B$, Distribution of the minimum stimulus threshold intensities necessary for eliciting EPSPs in the cells recorded in the lamina II ( $A$ ) and III $(B)$ from control and axotomized slices. $A$, Many lamina II neurons $(73 \%, 29$ of 40$)$ in control slices evoked EPSPs by high-threshold nerve stimulation $(40-80 \mathrm{~V})$. In axotomized slices, some lamina II neurons $(37 \%, 21$ of 57$)$ evoked EPSPs by high-threshold nerve stimulation (40-80 V), but other lamina II neurons $(54 \%, 31$ of 57$)$ evoked EPSPs by low-threshold nerve stimulation $(<20 \mathrm{~V})$. B. The majority of lamina III neurons before and after axotomy evoked EPSPs by low-threshold stimulation (5-20 V), i.e., control, $72 \%$ (23 of 32); axotomy, $81 \%$ (21 of 26). $C$, Spatial distribution of neurons receiving EPSPs driven by different afferent fibers. Closed circles and closed triangles indicate location of neurons receiving high-threshold monosynaptic and polysynaptic EPSPs, respectively. Open circles and open triangles indicate location of neurons receiving low-threshold monosynaptic and polysynaptic EPSPs, respectively. The distribution of neurons receiving low-threshold EPSPs extended from lamina III to lamina II after axotomy.

$(18 \%)$ received low-threshold EPSPs in normal spinal cord. Other changes observed in lamina II EPSPs were faster rise times of the EPSPs and an increase in multicomponent EPSPs, suggestive of enhanced polysynaptic potentials similar to that recorded in lamina III.

\section{Functional implications of $\mathbf{A} \boldsymbol{\beta}$ sprouting into substantial gelatinosa}

When taken together our histological and electrophysiological data strongly suggest that after nerve section and neuroma formation, the low-threshold mechanoreceptive afferent terminals that sprout into lamina II establish functional contacts with dorsal horn neurons that normally would exclusively receive $\mathrm{A} \delta$ and $\mathrm{C}$ nociceptor input. $\mathrm{A} \beta$ afferent fibers, which convey afferent information from low-threshold mechanoreceptive afferents, normally transmit tactile sensory information to the central neurons in deep dorsal horn laminae (III-V). Although many neurons in the superficial dorsal horn may receive $\mathrm{A} \beta$ input, it is predominantly polysynaptic, and there is a population of high-threshold nociceptive-specific cells that do not have a low-threshold mechanoreceptive field (Brown, 1981). C-fos labeling produced by $\mathrm{C}$-fiber stimulation after peripheral nerve section is decreased (Molander et al., 1992), in keeping with the hypothesis of a reduced synaptic input caused by atrophic changes in $\mathrm{C}$ fibers or 

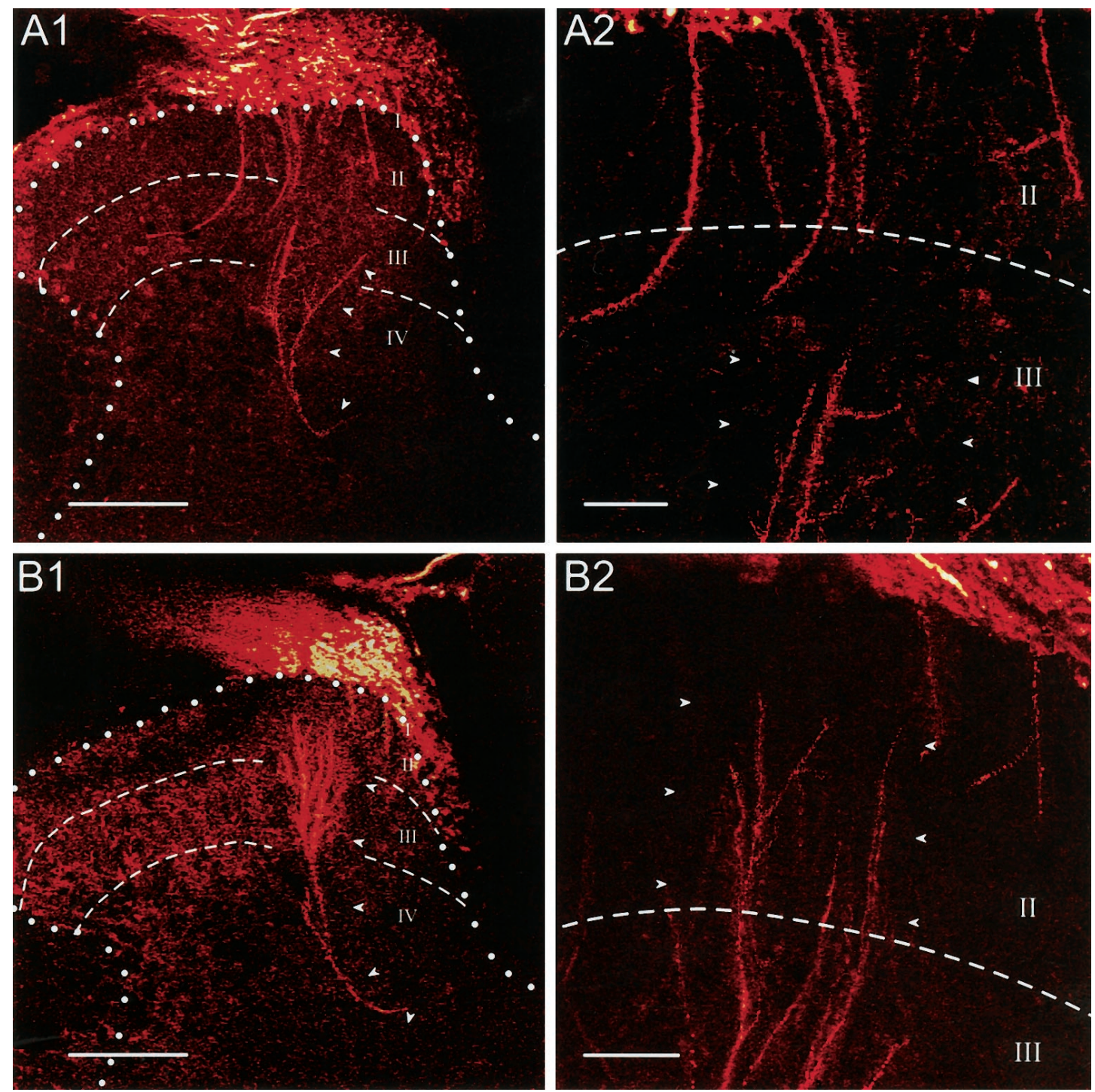

Figure 7. Confocal microscopic pictures of central afferent fibers anterogradely labeled with Texas Red-conjugated HRP in a control slice $(A)$ and an axotomized slice $(B)$. Arrowheads indicate central afferents with terminal arbors with a "flame-shaped" appearance. $A 2$ and $B 2$ are higher magnifications of $A 1$ and $B 1$, respectively. $A 2$, The terminals of the arbors are located within laminae III-IV. None of their terminal arbors penetrate dorsally into lamina II or more dorsally. B2, The laminar termination sites of some terminal of axotomized afferents extend more dorsally, laminae I-II. Scale bars: $A 1, B 1,250 \mu \mathrm{m} ; A 2, B 2,50 \mu \mathrm{m}$.

their synaptic terminals. The central nonmyelinated axons are reduced by approximately half after axotomy, but the central myelinated axons are not (Coggeshall et al., 1997). The degeneration of nonmyelinated axons might induce sprouting of $\mathrm{A} \beta$ afferent fibers and formation of inappropriate synaptic connections. Such changes could result in the activation of spinal neurons in superficial dorsal horn, which normally receive only $\mathrm{A} \delta$ fiber and $\mathrm{C}$ fiber input. These findings are in keeping with the generation of A fiber-mediated pain after nerve injury (McMahon et al., 1994; Woolf and Doubell, 1994). Furthermore, this could lead to inappropriate responses to innocuous peripheral stimuli. This may contribute to the pathophysiology of allodynia, in which light touch sensations are perceived as painful stimuli (Campbell et al., 1988; Nurmikko et al., 1990; Koltzenburg et al., 1992; Shortland and Woolf, 1993). The changes in $\mathrm{Na}^{+}$and $\mathrm{K}^{+}$ channel organization (Rizzo et al., 1995; Dib-Hajj et al., 1998; Everill and Kocsis, 1999) of cutaneous afferents after nerve injury could also provide for abnormal spontaneous firing of these neurons, which because of the inappropriate central connections, could account for spontaneous abnormal sensory sensations after nerve injury and neuroma formation.

\section{REFERENCES}

Ashur H, Vilner Y, Finsterbush A, Rousso M, Weinberg H, Devor M (1987) Extent of fiber regeneration after peripheral nerve repair: silicone splint vs. suture, gap repair vs. graft. Exp Neurol 97:365-374.

Arvidsson J, Ygge J, Grant G (1986) Cell loss in lumbar dorsal root ganglia and transganglionic degeneration after sciatic nerve resection in the rat. Brain Res 373:15-21.

Baba H, Doubell TP, Woolf CJ (1999) Peripheral inflammation facilitates $\mathrm{A} \beta$ fiber-mediated synaptic input to the substantia gelatinosa of the adult rat spinal cord. J Neurosci 19:859-867.

Beal JA, Bicknell HR (1985) Development and maturation of neurons in the substantia gelatinosa (SG) of the rat spinal cord. In: Development, organization and processing in somatosensory pathway (Rowe M, Willis Jr WD, eds), pp 23-30. New York: Wiley-Liss.

Blumberg H, Janig W (1982) Activation of fibers via experimentally produced stump neuromas of skin nerves: ephaptic transmission or retrograde sprouting? Exp Neurol 76: 468-482. 
Brown AG (1981) Organization in the spinal cord. New York: Springer. Brown AG, Rose PK, Snow PJ (1977) The morphology of hair follicle afferent fibre collaterals in the spinal cord of the cat. J Physiol (Lond) 272:779-797.

Brown PB, Gladfelter WE, Culberson JC, Covalt-Dunning D, Sonty RV, Pubols LM, Millecchia RJ (1991) Somatotopic organization of single primary afferent axon projections to cat spinal cord dorsal horn. J Neurosci 11:298-309.

Campbell JN, Raja SN, Meyer RA, Mackinnon SE (1988) Myelinated afferents signal the hyperalgesia associated with nerve injury. Pain 32:89-94.

Castro-Lopes JM, Coimbra A, Grant G, Arvidsson J (1990) Ultrastructural changes of the central scalloped $(\mathrm{C} 1)$ primary afferent endings of synaptic glomeruli in the substantia gelatinosa Rolandi of the rat after peripheral neurotomy. J Neurocytol 19:329-337.

Coggeshall RE, Lekan HA, Doubell TP, Allchorne A, Woolf CJ (1997) Central changes in primary afferent fibers following peripheral nerve lesions. Neuroscience 77:1115-1122.

Cummins TR, Waxman SG (1997) Downregulation of tetrodotoxinresistant sodium currents and upregulation of a rapidly repriming tetrodotoxin-sensitive sodium current in small spinal sensory neurons after nerve injury. J Neurosci 17:3503-3514.

Devor M, Govrin-Lippmann R (1986) Retrograde slowing of conduction in sensory axons central to a sciatic nerve neuroma. Exp Neurol 92:522-532.

Devor M, Keller CH, Ellisman MH (1990) Spontaneous discharge of afferents in a neuroma reflects original receptor tuning. Brain Res 517:245-250.

Devor M, Basbaum AI, Bennett GJ, Blumberg H, Campbell JN, Dembowsky KP, Guilbaud G, Janig W, Koltzenburg M, Levine JD, Otten UH, Portenoy RK (1991) Group report: mechanisms of neuropathic pain following peripheral injury. In: Towards a new pharmacotherapy of pain. Dahlem workshop report (Basbaum AI, Besson J-M, eds), pp 417-440. England: Wiley.

Dib-Hajj SD, Black JA, Cummins TR, Kenney AM, Kocsis JD, Waxman SG (1998) Rescue of alpha-SNS sodium channel expression in small dorsal root ganglion neurons after axotomy by nerve growth factor in vivo. J Neurophysiol 79:2668-2676.

Everill B, Kocsis JD, (1999) Reduction in potassium currents in identified cutaneous afferent dorsal root ganglion neurons after axotomy. J Neurophysiol 82:700-708.

Fried K, Devor M (1988) End-structure of afferent axons injured in the peripheral and central nervous system. Somatosens Mot Res 6:79-99.

Fried K, Govrin-Lippmann R, Rosenthal F, Ellisman MH, Devor M (1991) Ultrastructure of afferent axon endings in a neuroma. J Neurocytol 20:682-701.

Gerber G, Randic M (1989) Excitatory amino acid-mediated components of synaptically evoked input from dorsal roots to deep dorsal horn neurons in the rat spinal cord slice. Neurosci Lett 106:211-219.

Gerber G, Cerne R, Randic M (1991) Participation of excitatory amino acid receptors in the slow excitatory synaptic transmission in rat spinal dorsal horn. Brain Res 561:236-251.

Govrin-Lippmann R, Devor M (1978) Ongoing activity in severed nerves: source and variation with time. Brain Res 159:406-410.

Harper AA, Lawson SN (1985) Conduction velocity is related to morphological cell type in rat dorsal root ganglion neurones. J Physiol (Lond) 359:31-46.

Himes BT, Tessler A (1989) Death of some dorsal root ganglion neurons and plasticity of others following sciatic nerve section in adult and neonatal rats. J Comp Neurol 284:215-230.

Honmou O, Utzschneider DA, Rizzo MA, Bowe CM, Waxman SG, Kocsis JD (1994) Delayed depolarization and slow sodium currents in cutaneous afferents. J Neurophysiol 71:1627-1637.

Horch K (1988) Neurospecificity following sensory nerve regeneration. In: The current status of peripheral nervous regeneration (Gordon T, Stein RB, Smith PA, eds), pp 269-273. New York: Alan R. Liss.

Kapadia SE, LaMotte CC (1987) Deafferentation-induced alterations in the rat dorsal horn: I. Comparison of peripheral nerve injury vs. rhizotomy effects on presynaptic, postsynaptic, and glial processes. J Comp Neurol 266:183-197.

King AE, Thompson SW, Urban L, Woolf CJ (1988) The responses recorded in vitro of deep dorsal horn neurons to direct and orthodromic stimulation in the young rat spinal cord. Neuroscience 27:231-242.

Knyihar-Csillik E, Rakic P, Csillik B (1987) Transganglionic degen- erative atrophy in the substantia gelatinosa of the spinal cord after peripheral nerve transection in rhesus monkeys. Cell Tissue Res 247:599-604.

Kocsis JD, Ruiz JA, Waxman SG (1983) Maturation of mammalian myelinated fibers: changes in action-potential characteristics following 4-aminopyridine application. J Neurophysiol 50:449-463.

Kocsis JD, Preston RJ, Targ EF (1984) Retrograde impulse activity and horseradish peroxidase tracing of nerve fibers entering neuroma studied in vitro. Exp Neurol 85:400-412.

Koerber HR, Mirnics K, Brown PB, Mendell LM (1994) Central sprouting and functional plasticity of regenerated primary afferents. J Neurosci 14:3655-3671.

Kohama I, Agulian S, Kocsis JD (1998) Changes in synaptic transmission of rat spinal dorsal horn neurons after sciatic nerve transection. Soc Neurosci Abstr 24:393.

Koltzenburg M, Lundberg LE, Torebjork HE (1992) Dynamic and static components of mechanical hyperalgesia in human hairy skin. Pain $51: 207-219$.

McMahon SB, Lewin GR, Anand P, Ghatei MA, Bloom SR (1989) Quantitative analysis of peptide levels and neurogenic extravasation following regeneration of afferents to appropriate and inappropriate targets. Neuroscience 33:67-73.

McMahon SB, Kett-White R (1991) Sprouting of peripherally regenerating primary sensory neurones in the adult central nervous system. J Comp Neurol 304:307-315.

McMahon SB, Armanini MP, Ling LH, Phillips HS (1994) Expression and coexpression of Trk receptors in subpopulations of adult primary sensory neurons projecting to identified peripheral targets. Neuron 12:1161-1171.

Miller BA, Woolf CJ (1996) Glutamate-mediated slow synaptic currents in neonatal rat deep dorsal horn neurons in vitro. J Neurophysiol 76:1465-1476.

Molander C, Kinnman E, Aldskogius H (1988) Expansion of spinal cord primary sensory afferent projection following combined sciatic nerve resection and saphenous nerve crush: a horseradish peroxidase study in the adult rat. J Comp Neurol 276:436-441.

Molander C, Hongpaisan J, Grant G (1992) Changing pattern of c-FOS expression in spinal cord neurons after electrical stimulation of the chronically injured sciatic nerve in the rat. Neuroscience 50:223-236.

Munson JB, Collins WFI, Mendell LM (1988) Reinnervation of muscle spindles by groups Ia and Ib fibers is consistent with specificity in the reinnervation process. In: The current status of peripheral nervous regeneration (Gordon T, Stein RB, Smith PA, eds), pp 259-268. New York: Alan R. Liss.

Nurmikko TJ, Rasanen A, Hakkinen V (1990) Clinical and neurophysiological observations on acute herpes zoster. Clin J Pain 6:284-290.

Randic M, Jiang MC, Cerne R (1993) Long-term potentiation and longterm depression of primary afferent neurotransmission in the rat spinal cord. J Neurosci 13:5228-5241.

Richardson PM, Issa VM (1984) Peripheral injury enhances central regeneration of primary sensory neurones. Nature 309:791-793.

Richardson PM, Verge VM (1987) Axonal regeneration in dorsal spinal roots is accelerated by peripheral axonal transection. Brain Res 411:406-408.

Rizzo MA, Kocsis JD, Waxman SG (1995) Selective loss of slow and enhancement of fast $\mathrm{Na}^{+}$currents in cutaneous afferent dorsal root ganglion neurones following axotomy. Neurobiol Dis 2:87-96.

Sakai J, Honmou O, Kocsis JD, Hashi K (1998) The delayed depolarization in rat cutaneous afferent axons is reduced following nerve transection and ligation, but not crush: implications for injury-induced axonal $\mathrm{Na}^{+}$channel reorganization. Muscle Nerve 21:1040-1047.

Shortland P, Woolf CJ (1993) Chronic peripheral nerve section results in a rearrangement of the central axonal arborizations of axotomized $\mathrm{A}$ beta primary afferent neurons in the rat spinal cord. J Comp Neurol 330:65-82.

Shortland P, Woolf CJ, Fitzgerald M (1989) Morphology and somatotopic organization of the central terminals of hindlimb hair follicle afferents in the rat lumbar spinal cord. J Comp Neurol 289:416-433.

Todd AJ (1989) Cells in laminae III and IV of rat spinal dorsal horn receive monosynaptic primary afferent input in lamina II. J Comp Neurol 289:676-686.

Tong YG, Wang HF, Ju G, Grant G, Hokfelt T, Zhang X (1999) Increased uptake and transport of cholera toxin B-subunit in dorsal root 
ganglion neurons after peripheral axotomy: possible implications for sensory sprouting. J Comp Neurol 404:143-158.

Urban L, Randic M (1984) Slow excitatory transmission in rat dorsal horn: possible mediation by peptides. Brain Res 290:336-341.

Villiere V, McLachlan EM (1996) Electrophysiological properties of neurons in intact rat dorsal root ganglia classified by conduction velocity and action potential duration. J Neurophysiol 76:1924-1941.

Wall PD, Gutnick M (1974) Properties of afferent nerve impulses originating from a neuroma. Nature 248:740-743.

Welk E, Leah JD, Zimmermann M (1990) Characteristics of A- and $\mathrm{C}$-fibers ending in a sensory nerve neuroma in the rat. J Neurophysiol 63:759-766.

Willis WD, Coggeshall RE (1991) Sensory mechanisms of the spinal cord, Ed 2. New York: Plenum.

Woolf CJ (1987) Central terminations of cutaneous mechanoreceptive afferents in the rat lumbar spinal cord. J Comp Neurol 261:105-119.

Woolf CJ, Doubell TP (1994) The pathophysiology of chronic pain 190 increased sensitivity to low threshold A beta-fibre inputs. Curr Opin Neurobiol 4:525-534.

Woolf CJ, Fitzgerald M (1983) The properties of neurones recorded in the superficial dorsal horn of the rat spinal cord. J Comp Neurol 221:313-328.

Woolf CJ, Shortland P, Coggeshall RE (1992) Peripheral nerve injury triggers central sprouting of myelinated afferents. Nature 355:75-78.

Woolf CJ, Shortland P, Reynolds M, Ridings J, Doubell T, Coggeshall RE (1995) Reorganization of central terminals of myelinated primary afferents in the rat dorsal horn following peripheral axotomy. J Comp Neurol 360:121-134.

Yoshimura M, Jessell TM (1989) Primary afferent-evoked synaptic responses and slow potential generation in rat substantia gelatinosa neurons in vitro. J Neurophysiol 62:96-108.

Yoshimura M, Jessell T (1990) Amino acid-mediated EPSPs at primary afferent synapses with substantia gelatinosa neurones in the rat spinal cord. J Physiol (Lond) 430:315-335. 